\title{
NOTAS SOBRE EL GENERO BURSERA (BURSERACEAE) EN MICHOACAN (MEXICO). I. TRES ESPECIES NUEVAS DE LOS ALREDEDORES DE LA PRESA DEL INFIERNILLO, CON ALGUNOS DATOS RELATIVOS A LA REGION*
}

\author{
F. GUEVARA-FEFER**
}

\section{J. RZEDOWSKI***}

En contraste con muchos otros estados de la República Mexicana, en Michoacán existe una gran cantidad de estudios botánicos, la mayoría de los cuales fueron realizados por ilustres naturalistas principalmente del siglo pasado y comienzos de éste. Sin embargo, los trabajos realizados en tiempos más modernos son escasos y se refieren más bien a aspectos agrícolas, geográfico-económicos, etnobotánicos e históricos. Y a pesar de que la Flora es muy rica y diversa, las investigaciones taxonómicas efectuadas son de poca significación.

La Escuela de Biología de la Universidad Michoacana de San Nicolás de Hidalgo, inició en 1978 un proyecto denominado "Contribución al Estudio de los Recursos Bióticos del Estado de Michoacán”, que tiene como objetivo fundamental la realización de los inventarios florístico y faunístico que sirvan de base para la eventual elaboración de la Flora y la Fauna del Estado.

El área de botánica inició sus actividades hace poco más de un año; éstas se han centrado principalmente en una exaustiva revisión bibliográfica y recolección de especímenes botánicos. Hasta el momento se han colectado ca. de 1500 ejemplares y recopilado más de 150 citas bibliográficas de trabajos botánicos realizados en Michoacán. Los estudios taxonómicos se iniciaron con la revisión detallada de las familias más importantes, de las cuales la primera fue BURSERACEAE. La elección se hizo tomando en consideración que es una de las familias más ampliamente distribuidas en el Estado, es un grupo muy diverso que en la entidad está representado por aprox. 45 especies (casi la mitad de la totalidad de las especies del país) y constituye un elemento importantísimo tanto en la composición florística como en la estructura de los bosques tropicales que conforman la fisonomía de la región conocida como "TIERRA CALIENTE", ubicada en la porción occidental de la Cuenca del Río Balsas.

Esta cuenca, que representa el principal centro de diversidad del género Bursera, constitiuye la porción media del Estado de Michoacán, situada entre los paralelos $18^{\circ} 15^{\prime}$ y $19^{\circ} 15^{\prime}$ de latitud norte y entre los meridianos $100^{\circ} 45^{\prime}$ y $103^{\circ}$. Tal porción se encuentra limitada al norte por la Sierra del Centro, que forma parte del complejo orográfico del Eje Volcánico Transversal, hacia el sur está limitada por la

* El presente trabajo fue subsidiado por la SEP y la UMSNH, a través del Convenio N. 78/124, Clave $17 / 08 / 02 / 79$.

** Escuela de Biología, UNIVERSIDAD MICHOACANA DE SAN NICOLAS DE HIDALGO. Edificio "R", Ciudad Universitaria, Morelia. Michoacán.

*** Escuela Nacional de Ciencias Biológicas. INSTITUTO POLITECNICO NACIONAL. México 17, D. F. Becario de la COFAA del InSTITUTO POLITECNICO NACIONAL.

\section{3}

Guevara-Fefer F, Rzedowski J. 1980. Notas sobre el género Bursera (Burseraceae) en Michoacán (México). I. Tres especies nuevas de los alrededores de la presa del infiernillo, con algunos datos relativos a la región. Boletín de la Sociedad Botánica de México 39: 63-81. 
Sierra Madre del Sur, su límite occidental está determinado por las serranías que resultan de la confluencia de ambos sistemas orográficos en los límites con los Estados de Colima y Jalisco, al oriente la Tierra Caliente se continúa hacia el Estado de México y Guerrero. El Río Balsas penetra al Estado de Michoacán por el sureste, atravesando los Municipios de San Lucas, Huetamo y Churumuco, en donde se une al Río Grande o Tepalcatepec y tuerce hacia el sur para continuar a través de los Municipios de Arteaga y Lázaro Cárdenas hasta desembocar en el Oceano Pácífico.

Las partes más bajas de la Tierra Caliente están situadas entre 160 y $300 \mathrm{~m}$. de altitud, ubicándose principalmente en el área de influencia de la Presa del Infiernillo. Los suelos en general son de dos tipos, los característicos de laderas de cerros y los de valles, márgenes de ríos y arroyos. Los primeros suelen ser someros, de color café-rojizo, de textura arenoso-arcillosa y muy pedregosos, los últimos son profundos, de color claro, dependiendo su composición y textura del material de acarreo. Diversos factores fisiográficos, entre ellos el efecto de depresión interior, determinan el clima de la región; distribuyéndose en general los diferentes tipos climáticos, de acuerdo con el gradiente altitudinal. El tipo predominante presenta una temperatura media anual superior a $\operatorname{los} 26^{\circ} \mathrm{C}$ alcanzando en algunas localidades hasta $30-31{ }^{\circ} \mathrm{C}$ (e incluso en las zonas más bajas, como por ejemplo cerca del poblado de Infiernillo o al oeste de Nuevo Churumuco, hemos registrado temperaturas hasta de $56^{\circ} \mathrm{C}$ sobre el suelo durante el mes de junio), lo que significa que ésta sea una región de temperatura media anual de las más elevadas de México; la precipitación anual varía de $460 \mathrm{~mm}$ a $1000 \mathrm{~mm}$ correspondiendo los límites superiores hacia las serranías que bordean la región. Rasgo característico de este clima es el corto periodo de lluvias (junio-septiembre) seguido de una larga y fuerte temporada de sequía.

Tal caracterización ambiental determina la fisonomía y distribución de la vegetación que consiste principalmente de dos tipos, el Bosque Espinoso y el Bosque Tropical Caducifolio. El primero se desarrolla a manera de manchones y se ubica en los escasos valles existentes que son de poca extensión y significación, sobre suelos aluviales profundos; las especies más comunes son las siguientes: Prosopis laevigata, Acacia cymbispina, Ziziphus amole, Guaiacum coulteri, Cercidium praecox, Haematoxylon brasiletto y algunas cactáceas arborescentes. En algunas localidades con mayor humedad en el suelo es frecuente encontrar a Pithecellobium dulce y otras leguminosas espinosas.

El Bosque Tropical Caducifolio es característico de las laderas de cerros, se desarrolla entre los $160 \mathrm{~m}$ y aprox. los $1000 \mathrm{~m}$ de altitud; alcanza su mejor desarrollo por arriba de la cota de los $400 \mathrm{~m}$, siendo dominantes en este intervalo las siguientes especies del estrato arbóreo: Cordia elaeagnoides, Euphorbia schlechtendalii, Cyrtocarpa procera, Amphipterygium adstringens, Plumeria rubra, Haematoxylon brasiletto, Guazuma ulmifolia, Enterolobium cyclocarpum, Ceiba parvifolia, Cochlospermun vitifolium, Piscidia piscipula Pseudosmodingium perniciosum, Lonchocarpus spp, Bauhinia sp, Lysiloma spp. y numerosas especies del género Bursera como: B. fagaroides, B. copallifera, B. bipinnata, B. kerberi, B. bicolor, B. heteresthes, B. grandifolia, B.ariensis, B. aff. glabrifolia y otros árboles menos comunes (Rzedowski y McVaugh, 1966).

ebajo de los $500 \mathrm{~m}$. y a medida que se desciende a lo largo del gradiente 1 , la temperatura incrementa y la humedad se abate, lo que determina un 
aumento de aridez, lo cual a su vez se refleja en un cambio en la composición, fisonomía y estructura del bosque. Aumenta la abundancia de varias especies de cactáceas arborescentes como de los géneros Stenocereus, Pachycereus, Backebergia y otros. Otras especies del estrato arbóreo en orden de dominancia son: Euphorbia schlechtendalii, Bursera crenata, Bursera paradoxa, Randia watsonii, Bursera trimera, Jatropha spp., Bursera infernidialis, Bursera sarukhanii, Haematoxylon brasiletto, Bursera grandifolia, Bursera fagaroides, Plumeria rubra y Bursera spp.

Como se puede apreciar de las listas anteriores, el género Bursera está representado en los bosques, por numerosas especies, de las cuales tres representan nuevos taxa para la ciencia y que más adelante se describen.

De particular interés resulta el hecho de que estas tres especies con toda probabilidad son endémicas de la región del Infiernillo y sus alrededores. Estas especies así como otras del mismo género y algunas pertenecientes a las familias Leguminosae (M. Sousa, comunicación personal), Euphorbiaceae, Celastraceae y otras, completan un número relativamente significativo de endemismos. Tal fenómeno había sido ya observado y mencionado por Miranda $(1941,1943,1947,1948)$ para la porción oriental de la Cuenca del Balsas.

Estas observaciones sugieren que probablemente las distintas regiones ecológicas de la gran Depresión del Balsas representan a su vez diferentes centros de diversificación de ciertos grupos de plantas, hipótesis que podrá ser comprobada a medida que la flora de estas regiones sea conocida en detalle.

A continuación se describen las 3 especies nuevas del género Bursera, que comunmente coexisten y constituyen elementos del Bosque Tropical Caducifolio hacia las porciones de menor altitud (160-450 m.s.n.m.) de la Cuenca del Balsas en la región del Infiernillo y sus alrededores.

A falta de otra indicación, los ejemplares citados en el texto se encuentran depositados en los siguientes herbarios: Escuela de Biología de la Universidad Michoacana de San Nicolás de Hidalgo (EBUM), Escuela Nacional de Ciencias Biológicas del Instituto Politécnico Nacional (ENCB) y Herbario Nacional (MEXU), Instituto de Biología de la UNAM.

Bursera infernidialis Guevara et Rzedowski, sp. nov. (Fig. 1)

Arbor dioecia, 3-6 m alta, cortice laevi non exfolianti; folia plerumque trifoliolata, foliola obovata, $1.8-3.1 \mathrm{~cm}$ longa, $0.7-1.3 \mathrm{~cm}$ lata, apice rotundata marginibus dentatis glabrescentia; inflorescentiae paniculatae, cataphyllis in rosulis exterioribus cinctae, cataphylla oblonga, $2-15 \mathrm{~mm}$ longa; flores tetrameri, $\pm 3 \mathrm{~mm}$ longi, \pm 2.5 $\mathrm{mm}$ lati, ovarium biloculare; drupae bivalvatae, subgloboso-applanatae, breviter apiculate, 7-9 $\mathrm{mm}$ longae, 5.5-7 $\mathrm{mm}$ latae, glabrae, pyrenae nigrae, pseudoarillo rubro partim indutae.

Arbol dioico de 3-6 m. de alto, de corteza lisa, no exfoliante, grisáceo-rojiza, las ramillas jóvenes rojizas, resinosas y de aroma suave. Hojas compuestas, dispuestas en rosetas en los extremos de las ramillas tanto terminales como laterales y esparcidas a lo largo de las ramillas terminales jóvenes; típicamente trifolioladas (excepcionalmente de $4-5$ foliolos), de $3-7 \mathrm{~cm}$ delargo e incluso más largas en las ramillas vigorosas. Foliolos de forma obovada, ápice redondeado y margen dentado desde cerca de la base hasta el ápice; la mayoría de los dientes simples y redondeados, en número 

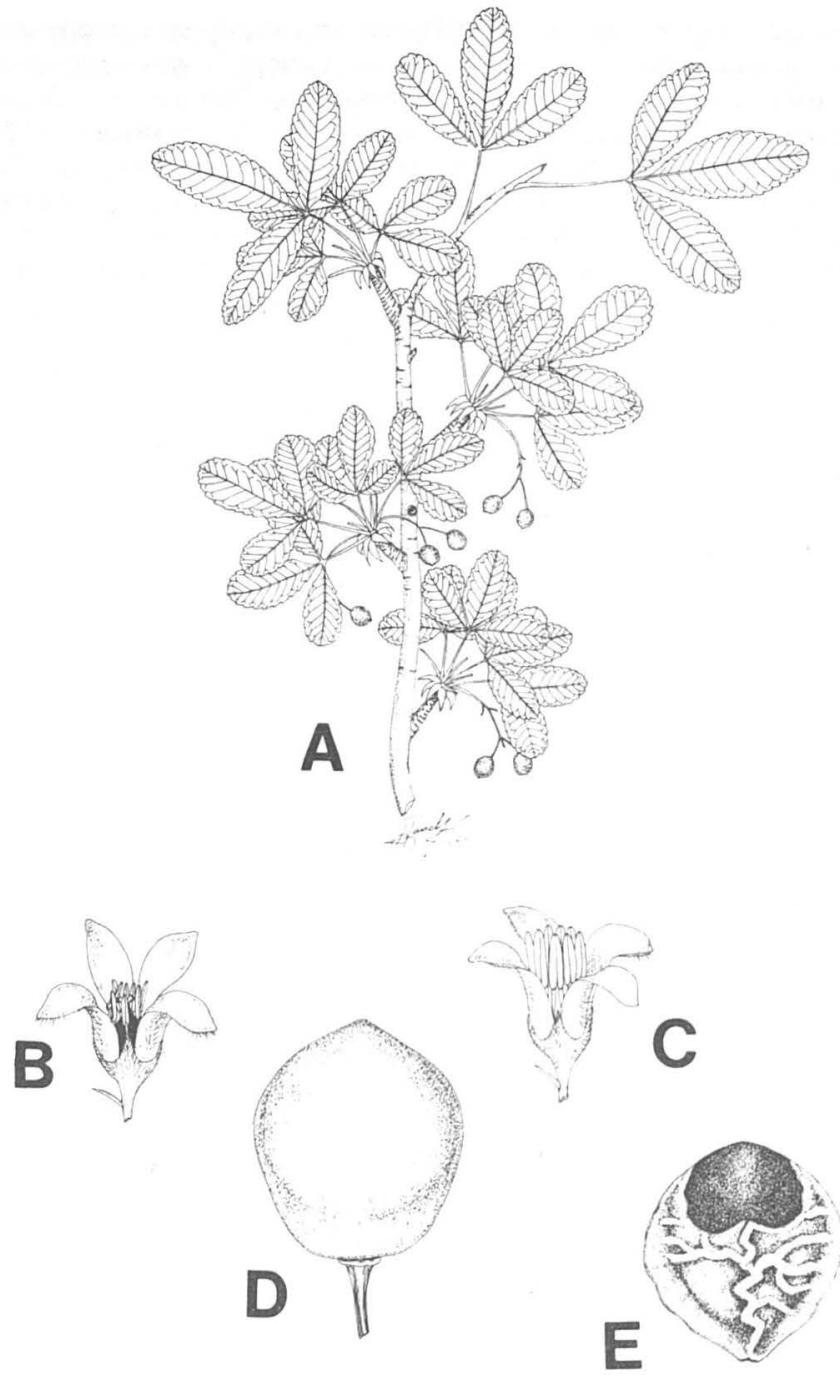

Fig. 1. Bursera infernidialis Guevara et Rzedowski. A. Rama con frutos, X 0.3; B. Flor femenina, X 6.0; C. Flor Masculina, X 6; D. Fruto, X 3.0; E. Semilla parcialmente envuelta por el pseudoarilo, X 4.5 . 
de 10 - 20 por lado; algo asimétricos, de base atenuada, venas amarillentas y conspicuas en ambas caras; pubescentes tanto en el haz como el envés al principio, glabrescentes a la madurez, persistiendo la pubescencia principalmente en la vena central y las laterales por el envés, los pelos hasta de $1 \mathrm{~mm}$ de largo. Los foliolos laterales de $1.8-3.1 \mathrm{~cm}$ de largo y $0.7-1.3 \mathrm{~cm}$ de ancho; los terminales hasta 1.5 veces más largos que los laterales, de $2.1-4.5 \mathrm{~cm}$ de largo y $1-1.5 \mathrm{~cm}$ de ancho. Peciolo de $\pm 1.3 \mathrm{~cm}$ de largo, ligeramente ensanchado hacia la base, densamente pubescente al principio, esencialmente glabro a la madurez, aplanado en ambas caras y acanalado en la superior que es menos pubescente que la inferior y con manchoncitos de pelos blanquecinos en el punto de inserción de los foliolos. Inflorescencias dispuestas en los extremos de las ramillas terminales y laterales, rodeadas en su base por varias series de catáfilas que miden de $2-15 \mathrm{~mm}$ de largo y $2-4 \mathrm{~mm}$ de ancho, precozmente deciduas, de forma oblonga con el ápice puntiagudo rígido e incurvado, densamente pubescentes en ambas caras, con pelos blanquecinos, entre los que se encuentran dispersos pelos glandulosos amarillentos; las series internas de catáfilas sucesivamente mayores. Inflorescencias paniculadas, insertas en la base de las hojas jóvenes, de $3-3.5 \mathrm{~cm}$ de largo; las femeninas con menos flores (3-5) que las masculinas (hasta 10); brácteas y bracteolas linear-lanceoladas, densamente pubescentes, los pelos blanquecinos conspicuos y puntiagudos; los pedúnculos, pedicelos y ejes igualmente pubescentes. Flores provistas de pequeñas bracteolas linear-lanceoladas de 1.5-2 $\mathrm{mm}$ de largo y menos de $1 \mathrm{~mm}$ de ancho, las brácteas de base ensanchada, del doble del largo y ancho de las bracteolas. Flores femeninas de \pm 3 $\mathrm{mm}$ de largo y $\pm 2.5 \mathrm{~mm}$ de ancho, sobre pedicelos de $5-11 \mathrm{~mm}$ de largo. Sépalos 4 , de $0.7-1 \mathrm{~mm}$ de largo y de $0.5-0.7 \mathrm{~mm}$ de ancho, estrigoso-pubescentes con escasos pelos glandulosos amarillentos esparcidos y conspicuos en los bordes, glabros en la cara interior. Pétalos 4 , de 2.5 a $3 \mathrm{~mm}$ de largo y de $1-1.3 \mathrm{~mm}$ de ancho, con los ápices refiejos, de colôr cremá anariliento, con pelos esparcidos concentrados principalmente hacia el ápice y la costa central. Ovario bicarpelar, bilocular, estilo bífido, estigma papiloso. Estaminodios 8 , de $\pm 1.5 \mathrm{~mm}$ de largo, filamentos de $1 \mathrm{~mm}$ de largo, anteras de $\pm 0.5 \mathrm{~mm}$ de largo. Flores masculinas de \pm $\pm 3 \mathrm{~mm}$ de largo y $\pm 2.5 \mathrm{~mm}$ de largo y de $0.5-1 \mathrm{~mm}$ de ancho; de forma, color y pubescencia similares a los de las flores femeninas. Estambres 8, fértiles, de 1.5- 2 $\mathrm{mm}$ de largo; filamentos de $0.5-1 \mathrm{~mm}$ de largo, anteras de $1-1.5 \mathrm{~mm}$ de largo; gineceo residual de menos $0.5 \mathrm{~mm}$. En las flores de ambos sexos los pétalos son oblongo-oblanceolados y los sépalos triangulares.

Infrutescencias de $3.5-4.5 \mathrm{~cm}$ de largo, con pocos frutos (1-3), pedicelo y pedúnculo glabros, este último estriado; drupas bivalvadas, subesférico-aplanadas (ampliamente ovoides), de 5.5- $7 \mathrm{~mm}$ de ancho y $7-9 \mathrm{~mm}$ de largo, glabras y cortamente apiculadas. Pseudoarilo de color rojo intenso, que cubre la parte media inferior de una de las caras del endocarpio, los cantos y casi totalmente la otra cara; endocarpio de color negro con una de sus caras ligeramente aplanada, la otra muy redondeada, de $5-6 \mathrm{~mm}$ de largo y $4-5 \mathrm{~mm}$ de ancho.

Florece de mediados de mayo a mediados de julio y desprende sus hojas hacia el final de año.

Tipo: MEXICO: MICHOACAN: $13 \mathrm{~km}$ al SE de Poturo y a $5 \mathrm{~km}$ al NO de La Candelaria, sobre el camino a Nuevo Churumuco, Mpio. de La Huacana; bosque tropical caducifolio muy perturbado, sobre lomeríos de mediana a suave pendiente, 
suelos someros y pedregosos, alt. $450 \mathrm{~m}$; 15.IX. 78, hojas y frutos maduros: F. Guevara F. 10 (ENCB).

Bursera infernidialis representa un taxón bien caracterizado, perteneciente a la sección Bullockia y parece estar relacionada con un grupo de especies que presentan pocos foliolos, dentados y pubescentes, inflorescencias paniculadas relativamente cortas y paucifloras, con flores pequeñas de color claro, frutos elipsoidales a ovoides o subesféricos, con el endocarpio de color negro cubierto por un pseudoarilo de color rojo intenso que cubre la parte media inferior de una de las caras, los cantos y casi totalmente la otra cara. Indudablemente las mayores afinidades se presentan con otra especie aun sin describir del Estado de Oaxaca, cn cuya definición taxonómica actualmente se está trabajando.

Presenta asimismo cierta semejanza con Bursera coyucensis Bullock, con la cual coexiste en buena parte de su área de distribución, pero ésta última se diferencia por presentar hojas compuestas con 3 a 5 pares de foliolos, frutos apiculados y porque tanto sus hojas como las partes florales llevan abundante pubescencia de pelos largos de color amarillento claro. Con Bursera biflora (Rose) Standl, presenta grandes similitudes en cuanto a la morfología de la hoja, pero se diferencia porque en esta última las catáfilas son muy angostas y cortas, los foliolos más pequeños con pelos blanquecinos más cortos y en número de 1 o 3 , con pocos dientes en los $2 / 3$ superiores; las inflorescencias son más pequeñas y tanto el cáliz como la corola son más densamente pubescentes. Con Bursera heteresthes Bullock presenta analogía en cuanto al tamaño, forma y pubescencia de las flores, pero ésta última tiene foliolos muy grandes conspicua y densamente pubescentes, inflorescencias paucifloras abiertas y muy largas, con los pedicelos muy largos; los foliolos presentan numerosos dientes simples o dobles y ápice acuminado.

Material adicional utilizado en la descripción:

MEXICO: MICHOACAN: Dry hills 13 miles southwest of La Huacana, alt. 180 m, 26.X.62 (hojas y flores), R. McVaugh 21950 (ENCB); $7 \mathrm{~km}$ al SE de Poturo, sobre el camino a Nuevo Churumuco, Mpio. de La Huacana, alt. 500 m, 15.X.78 (hojas y frutos), F. Guevara 6; Las Pilitas, a $17 \mathrm{~km}$. al E de Zicuirán, rumbo a Nuevo Churumuco, Mpio de La Huacana, alt. 310 m, 16.IX.78 (hojas y frutos), F. Guevara $34 ; 5 \mathrm{~km}$ al NE de Zicuirán, rumbo a La Huacana, Mpio. de La Huacana, alt. $240 \mathrm{~m}$, 11.X.78 (hojas), F. Guevara y J. Rzedowski $48 ; 23 \mathrm{~km}$ al $\mathrm{N}$ de Infiernillo, ca. del Hinduri, Mpio. de Arteaga, alt. 400 m, 11.X.78 (hojas), F. Guevara y J. Rzedowski 62; La Cañada de Huaricho, $9 \mathrm{~km}$ al SE de Poturo, sobre el camino a Nvo. Churumuco, Mpio. de La Huacana, alt. 390 m, 24.VI.79 (hojas, flores y frutos), F. Guevara y L. Ortíz 510; ibid., 24.VI.79 (hojas y flores), F. Guevara y L. Ortíz 511; ibid., 24.VI.79 (hojas, flores y frutos), F. Guevara y L. Ortíz 512; ca. de La Cañada de Huaricho, $10 \mathrm{~km}$ al SE de Poturo, rumbo a Nuevo Churumuco, Mpio. de La Huacana, alt. $370 \mathrm{~m}, 24$. VI.79 (hojas, flores y frutos), F. Guevara y L. Ortíz 513; $2 \mathrm{~km}$ al E de Las Pilitas, rumbo a Zicuirán, Mpio. de La Huacana, alt. $190 \mathrm{~m}$, 25.VI.79 (hojas y flores), F. Guevara y L. Ortíz 537; $3 \mathrm{~km}$ al NE de Zicuirán, Mpio. de La Huacana, alt. 250 m, I.VII.79 (hojas y frutos), F. Guevara y J. Díaz 588; ibid., 1.VII.79 (hojas y botones florales), F. Guevara y J. Díaz 594; ibid., 1.VII.79 (hojas y flores), F. Guevara y J. Díaz 596; entre San Pedro Barajas y la desv. Infiernillo-Arteaga, Mpio. de La Huacana, alt. 240 m, 1.VII.79 (hojas), F. Guevara y J. Díaz 598; $29 \mathrm{~km}$ al SE de Cuatro Caminos, rumbo a San Pedro Barajas, Mpio. de Nueva Italia, 
alt. 340 m. 19.VII.79 (hojas, botones y flores), F. Guevara, M. Sousa, L. Ortíz, J. Díaz, A. Morelos y R. Sousa 689; ibid., 19.VII.79 (hojas y frutos), F. Guevara, M. Sousa, L. Ortíz, J. Díaz, A. Morelos y R. Sousa 6; ibid. 19. VII.79 (hojas y frutos), F. Guevara, M. Sousa, L. Ortíz, J. Díaz, A. Morelos, R. Sousa 699; 29 km al NE de Puerto San Salvador, 698 por la carr. Arteaga-Cuarto Caminos, Mpio. de Arteaga, atl. 370 m, 20 VII. 79 (hojas), F. Guevara, M. Sousa, L. Ortíz, J. Díaz, A. Morelos, R. Sousa $732 ; 11 \mathrm{~km}$ al SE del crucero Infiernillo- Arteaga, rumbo al Infiernillo, Mpio. de Arteaga, alt. 340 m. 21.VIII.79 (hojas), F. Guevara, L. Ortíz, J. Díaz y R. Sánchez 793; alrededores del Hinduri, $30 \mathrm{~km}$ al NO de Infiernillo, Mpio. de Arteaga, alt. 405 m, 24.VIII.79 (hojas), F. Guevara, L. Ortíz, J. Díaz y R. Sánchez 800; Cupuancillo, Mpio. de La Huacana, alt. 430 m, $20 . I X .79$ (frutos), X. Madrigal S. 3390; $4 \mathrm{~km}$ al SE de San Pedro Barajas, Mpio. de La Huacana, alt: 220 m, 12.X.79 (hojas y frutos), F. Guevara, L. Ortíz, J. Díaz y R. Sánchez 833.

GUERRERO: $12 \mathrm{~km}$. al SE de la cortina de la presa de Infiernillo, rumbo a la Unión, Mpio. de Coahuayutla, alt. $160 \mathrm{~m}, 25$. VIII.79, (hojas), F. Guevara, L. Ortíz, J. Díaz y R. Sánchez 808.

Bursera paradoxa Guevara et Rzedowski, sp. nov. (Fig. 2)

Arbor dioecia, 3-6 m alta, cortice laevi non exfolianti; folia imparipinnata, 6-8juga, rhachide exalata, foliola linearia, $5-6 \mathrm{~cm}$ longa, 0.5-1 $\mathrm{mm}$ lata, glabra; inflorescentiae fasciculatae, pauciflorae; flores masculi pentameri, 4.5-5.5 mm longi; flores feminei trimeri, 3-4 mm longi, ovarium triloculare; drupae trivalvatae, globoso-pyramidales, 5-8 mm longae, 5-7 latae, glabrae, fere sessiles, pyrenae pseudoarillo pallido omnino indutae.

Arbol dioico de $3-6 \mathrm{~mm}$ de alto, de corteza lisa, la externa delgada de color gris claro (no exfoliante), la segunda capa de color verde claro y la más interna de color rojo obscuro, con látex blanco crema, sin aroma. Las ramillas terminales algo divaricadas y colgantes. Hojas imparipinnadas, dispuestas en rosetas en los extremos de las ramillas tanto terminales como laterales; esparcidas en las ramillas largas; en número de hasta 10 , miden hasta $11.5 \mathrm{~cm}$ de largo y $9-10 \mathrm{~cm}$ de ancho. Foliolos 6-8 pares, lineares, de $5-6 \mathrm{~cm}$ de largo y 0.5 a $1 \mathrm{~mm}$ de ancho; los foliolos intermedios más largos que los superiores e inferiores, el terminal ligeramente mayor o menor que el par inmediato inferior. Peciolo de 1.8 a $2.5 \mathrm{~cm}$ de largo, ligeramente ensanchado hacia la base, raquis de la misma forma, textura y ancho que los foliolos, ligedesprovisto de alas; distancia interfoliar de $7-11 \mathrm{~mm}$. Todas las partes foliares glabras y cubiertas de una delgada capa cerosa. Inflorescencias fasciculadas entre las hojas jóvenes, con pocas flores (1-8 por fascículo). Flores provistas de dos pequeñas bracteolas triangular-lanceoladas, de $0.5-2.1 \mathrm{~mm}$ de largo y de $0.5-0.8 \mathrm{~mm}$ de ancho, cubiertas de glándulas blanquecinas cortas y dispersas, esencialmente en los bordes; brácteas de $2.5 \mathrm{~mm}$ de largo y $0.5 \mathrm{~mm}$ de ancho de forma y textura similares a las de las bracteolas. Inflorescencias masculinas con 2- 8 flores, éstas pentámeras, sobre pedicelos de $0-3 \mathrm{~mm}$ de largo esparcidamente pubescentes; sépalos triangulares de color rojizo claro, con glándulas subsésiles en los bordes, subiguales, de $2-3 \mathrm{~mm}$ de largo y $1 \mathrm{~mm}$ de ancho; pétalos ascendentes, oblanceolados, con el ápice incurvado, glabros y de $4.5-5.5 \mathrm{~mm}$ de largo y de $2-2.5 \mathrm{~mm}$ de ancho, 


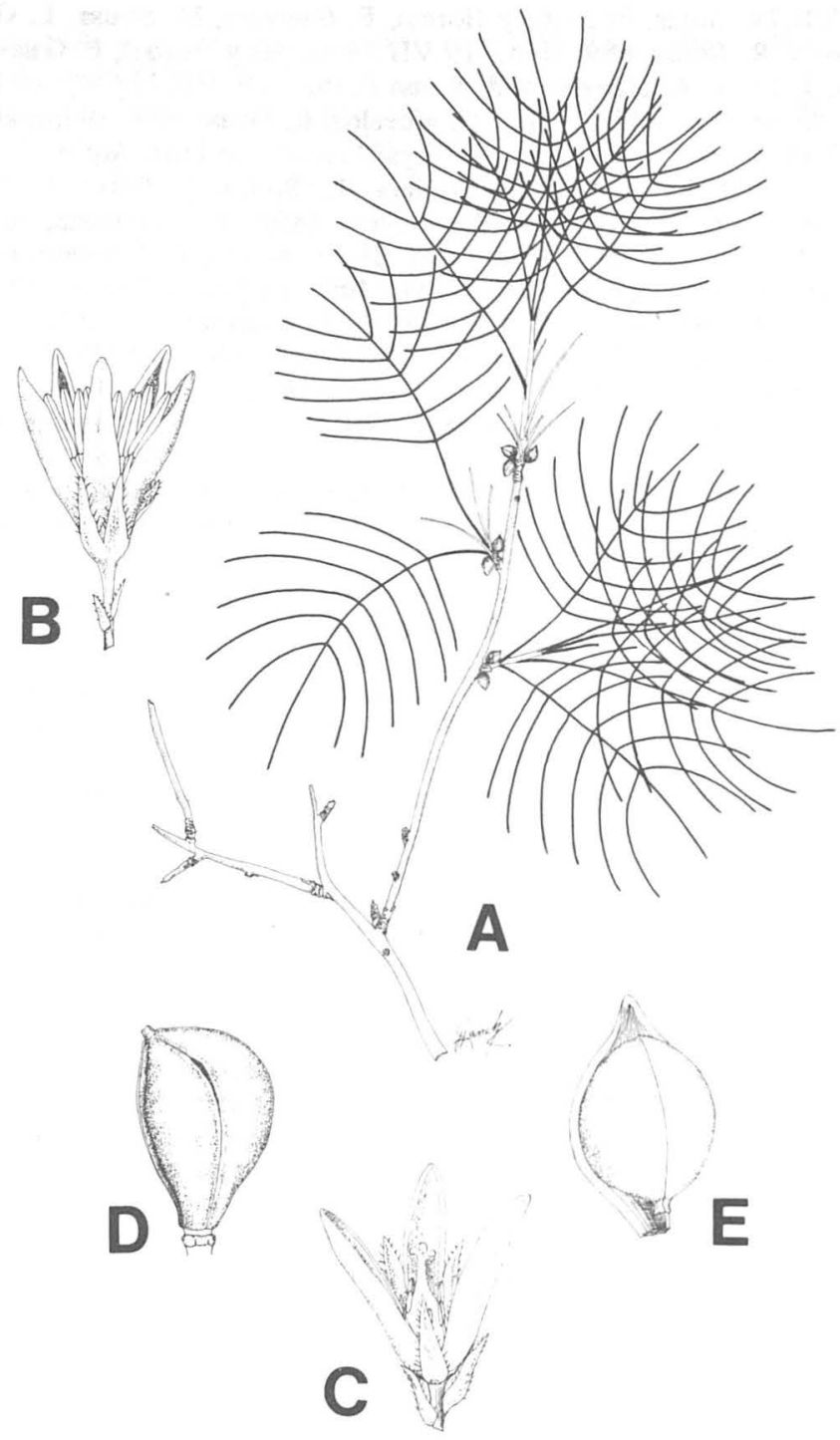

Fig. 2. Bursera paradoxa Guevara et Rzedowski. A. Rama con frutos, X 0.3; B. Flor masculina, X 3.0; C. Flor femenina, X 6.0; D. Fruto, X 3.0, E. Semilla totalmente cubierta por el pseudoarilo, X 3.0. 
de color rojizo claro. Estambres 10, libres, glabros, dispuestos en dos series de 5, la exterior de tamaño ligeramente menor, opuesta a los pétalos e inserta en sus bases, la interior opuesta a los sépalos e inserta por debajo del disco, miden de $3-4 \mathrm{~mm}$ de largo; filamentos de $1.5-2.5 \mathrm{~mm}$ de largo, ensanchados hacia la base, anteras de $1.5-2 \mathrm{~mm}$ de largo; ovario residual de menos $0.5 \mathrm{~mm}$ de largo. Inflorescencias femeninas con $1-5$ flores por fascículo, sus flores trímeras, sobre pedicelos de 0.5 - $1 \mathrm{~mm}$ de largo, con glándulas pequeñas blanquecinas y esparcidas; sépalos triangulares de color rojizo claro, con glándulas subsésiles en los bordes, subiguales, de $2-2.5 \mathrm{~mm}$ de largo y de $1 \mathrm{~mm}$ de ancho; pétalos ascendentes, oblanceolados, con el ápice incurvado, glabros y de $3-4 \mathrm{~mm}$ de largo y de $2 \mathrm{~mm}$ de ancho. Estambres 6 , libres, glabros, estériles, dispuestos en la misma forma que los de las flores masculinas y de $1.5 \mathrm{~mm}$ de largo; filamentos de $0.5 \mathrm{~mm}$ de largo ensanchados hacia la base, anteras de $1 \mathrm{~mm}$ de largo; ovario tricarpelar, trilocular, estilo trífido, estigma cortamente papiloso.

Drupas trivalvadas globoso-piramidales, glabras, de color grisáceo a la madurez, miden de $5-8 \mathrm{~mm}$ de largo y de $5-7 \mathrm{~mm}$ de ancho, cortamente pediceladas, casi sésiles (pedicelos de $1-2 \mathrm{~mm}$ de largo); valvas subiguales, reticuladas y puntiagudas; pseudoarilo de color claro, cubriendo totalmente el endocarpio que mide $5 \mathrm{~mm}$ de largo y $4 \mathrm{~mm}$ de ancho, con dos caras planas y la otra redondeada.

Florece de mediados de mayo a principios de julio y desprende sus hojas a finales del año.

Nombre local: "cabello de angel", "pinillo".

Tipo: MEXICO: MICHOACAN: $2 \mathrm{~km}$ al S de la desviación Infiernillo-Arteaga, rumbo a la presa del Infiernillo, Municipio de Arteaga; bosque tropical caducifolio con cactos arborescentes, sobre suelos someros y pedregosos, en lomeríos de suave a mediana pendiente, altitud $320 \mathrm{~m} ; 1^{\circ}$ julio de 1979, hojas y frutos maduros; F. Guevara F. y J. Díaz C. 609 (ENCB).

Excepto por el carácter no exfoliante de la corteza externa, indudablemente Bursera paradoxa pertenece a la sección Bursera y aunque sus relaciones no resultan del todo claras y a reserva de realizar un estudio comparativo más extenso y profundo, en principio parece tener ciertas afinidades con un grupo de especies que se distribuyen en habitats similares y que poseen también foliolos angostos como son: B. galeottiana Engl., B. morelensis Ramírez, B. microphylla A Gray., B. multifolia (Rose) Engl. y B. arida (Rose) Standl. De las cuatro primeras se diferencia por sus foliolos más angostos, largos, menos numerosos, así como por la distancia interfoliar que es mayor. Además, mientras en ellas las flores son más numerosas, los pedicelos de las flores y frutos más largos y éstos últimos comunmente curvados, en B. paradoxa las flores femeninas son casi sésiles, poco numerosas y los frutos cortamente pedicelados. Con B. arida coincide en éstos últimos caracteres y parcialmente en la corteza (pues no es raro encontrar individuos de la citada especie con la corteza externa de color rojizo poco exfoliante); sin embargo los foliolos de B. arida son menos numerosos, más pequeños y anchos, sus flores más pequeñas y pubescentes. Con respecto a su distribución B. paradoxa se encuentra geográficamente separada de los taxa antes mencionados y confinada a la parte más baja de la Cuenca del Balsas hacia la porción central de Michoacán y el extremo noroeste de Guerrero.

De particular interés resulta el carácter no exfoliante de la corteza externa de esta especie aunque cabe mencionar que si bien tal carácter es relativamente constante 
en las diferentes poblaciones analizadas, no es raro encontrar algunos individuos que presentan hacia las porciones basales del tronco pequeñas tiras delgadas y angostas de color rojo-cenizo y otros mucho menos frecuentes en las porciones superiores del tronco.

McVaugh y Rzedowski (1965) y Rzedowski y Kruse (1979) habían sugerido el carácter exfoliante de la corteza externa, de colores vivos, las drupas trivalvadas, ovario trilocular y las flores trímeras a pentámeras como carácteres exclusivos de un conjunto de especies, que se agrupan tentativamente en la sección Bursera; mientras que el carácter no exfoliante de la corteza externa de color grisáceo rojizo, las drupas bivalvadas, ovario bilocular y las flores tetrámeras, caracterizaban a un grupo de especies que provisionalmente agruparon en la sección Bullockia del género en cuestión. Tomando en consideración el carácter no exfoliante de la corteza externa de algunas de las especies de la sección Bursera como B. paradoxa, una nueva especie (en cuya definición taxonómica se está trabajando) y otras como B. arida que presentan algunas poblaciones de corteza poco exfoliante; ahora se debe señalar que el carácter no exfoliante, que tampoco es del todo constante en la sección Bullockia, no parece ser exclusivo de ella y por lo tanto tal rasgo resulta secundario en la separación y diferenciación de las dos secciones.

La presencia del carácter no exfoliante de algunos de los miembros de la sección Bursera viene a reforzar la proposición hecha por el último de los autores (1979) en el sentido de considerar el carácter exfoliante como anterior o primitivo en todo este grupo de plantas y así B. paradoxa parecería representar más bien un taxón relativamente evolucionado o derivado que manifiesta la tendencia hacia el carácter liso de la corteza externa. O bien, por otro lado, tal carácter, en principio atípico de la sección Bursera, podría poner de manifiesto otra sugerencia en relación con los fenómenos de convergencia adaptativa de ciertos rasgos vegetativos que se presentan aún en grupos relativamente bien diferenciados. Y así, a las tendencias evolutivas observadas como por ejemplo la reducción del número de foliolos y la similitud de formas de los mismos; se puede agregar ahora la tendencia hacia la corteza poco o nada exfoliante.

A propósito de convergencia, cabe poner de manifiesto la gran similitud entre las hojas de B. paradoxa y las hojas de Commiphora kraeuseliana Heine, especie perteneciente a un género emparentado con Bursera y endémica del suroeste de Africa. Aunque no se dispone de ejemplares de herbario, pero basándose en las descripciones escritas y fotografías (Van der Walt, 1974), las hojas de ambas especies parecen diferir sólo escasamente en el tamaño de las mismas, siendo sorprendente la similitud en cuanto al número, forma y estructura de las partes foliares.

Material adicional utilizado en la descripción:

MEXICO: MICHOACAN: $6 \mathrm{~km}$ al $\mathrm{N}$ de Nuevo Churumuco, sobre el camino a Poturo, Mpio. de La Huacana, alt. 225 m. 15.IX.78 (hojas), F. Guevara 13; 5 km al NE de Zicuirán, rumbo a La Huacana, alt. 240 m, 11.X.78 (hojas y frutos), F. Guevara y J. Rzedowski 45; ibid., 11.X.78 (hojas y frutos), F. Guevara y J. Rzedowski 49; entre La Laja y Zicuirán, a orillas de la presa, Mpio. de La Huacana, alt. 220 m, 30.IV.79 (botones), F. Guevara, L. Ortíz, J. Díaz y R. Sánchez 420; $11 \mathrm{~km}$ al SE de Poturo, rumbo a Nvo. Churumuco, Mpio. de La Huacana, alt. 370 m, 24.VI.79 (hojas y frutos), F. Guevara y L. Ortíz $518 ; 2 \mathrm{~km}$ al S de La Candelaria, rumbo a Nvo. Churumuco, Mpio. de La Huacana, alt. 340 m, 24.VI.79 (flores, hojas y frutos), 
F. Guevara y L. Ortíz 519; ibid., 24 .VI.79 (hojas, frutos y flores), F. Guevara y L. Ortíz 520; $2 \mathrm{~km}$ al 0 de Nuevo Churumuco, Mpio. de Nuevo Churumuco, alt. 180 m. 25.VI.79 (hojas y flores), F. Guevara y L. Ortíz 524; $27 \mathrm{~km}$ al O de Nuevo Churumuco, rumbo a Zicuirán, Mpio. de La Huacana, alt. 200 m, 25.VI.79 (hojas, botones y frutos), F. Guevara y L. Ortíz 533; $5 \mathrm{~km}$ al NE de Zicuirán, sobre el camino a La Huacana, Mpio. de La Huacana, alt. 240 m, 25.VI.79 (botones y hojas), F. Guevara y L. Ortíz 554; ibid., 25.VI.79 (hojas y botones), F. Guevara y L. Ortíz $555 ; 3 \mathrm{~km}$ al NE de Zicuirán, Mpio. de La Huacana, alt. $250 \mathrm{~m}, 30 . V I .79$ (hojas y frutos), F. Guevara y J, Díaz 587; entre San Pedro Barajas y la desv. Arteaga-Infiernillo, Mpio. de Nueva Italia, alt. 240 m, 1.VII.79 (hojas), F. Guevara y J. Díaz 599; $2 \mathrm{~km}$ al S de la desv. Infiernillo-Arteaga, rumbo a Infiernillo, Mpio. de Arteaga, alt. 320 m, 1.VII.79 (hojas maduras), F. Guevara y J. Díaz 601; alrededores del Hinduri, $30 \mathrm{~km}$ al NO de Infiernillo, Mpio. de Arteaga, alt. $390 \mathrm{~m}, 1 . V I I .79$ (hojas), F. Guevara y J. Díaz 622; $29 \mathrm{~km}$ al SE de Cuatro Caminos, rumbo a San Pedro Barajas, Mpio. de Nueva Italia, alt. 340 m. 19.VII.79 (hojas y frutos), F. Guevara, M. Sousa, L. Ortíz, J. Díaz, A. Morelos y R. Sousa 697; $1 \mathrm{~km}$ al S del crucero Infiernillo-Arteaga, rumbo a Playa Azul, Mpio. de Arteaga, alt. 360 m, 19.VII.79 (hojas y flores), F. Guevara, M. Sousa, L. Ortíz, J. Díaz, A. Morelos y R. Sousa 703; Cupuancillo, Mpio. de La Huacana, alt. 430 m, 20.IX.79 (fr), X. Madrigal. 3391; Carr. Cuatro Caminos-Playa Azul, $3 \mathrm{~km}$ al SE de la desviación a Infiernillo, Mpio. de Arteaga, alt. $375 \mathrm{~m}, 17 . X .79$ (hojas y frutos), J. Soto y G. Silva 1633 (MEXU); $4 \mathrm{~km}$ al SE de San Pedro Barajas, Mpio. de La Huacana, alt. 220 m, 25.X.79 (hojas y frutos), F. Guevara, J. Díaz y R. Sánchez 807.

GUERRERO: $12 \mathrm{~km}$ al SE de la cortina de la presa de Infiernillo, rumbo a la Unión, Mpio. de Coahuayutla, alt. $160 \mathrm{~m}, 12 . X .79$ (hojas y frutos), F. Guevara, J. Díaz y R. Sánchez 832.

\section{Bursera sarukhanii Guevara et Rzedowski, sp. nov. (Fig. 3)}

Arbor dioecia, 4-6 m alta, cortice laevi non exfolianti; folia imparipinnata, 4-6juga, rhachide alata, foliola oblanceolata, $5.5-9.5 \mathrm{~cm}$ longa, $1.2-2.5 \mathrm{~cm}$ lata, apice acuta vel breviter acuminata, marginibus dentatis, utrinque tomentosa; inflorescentiae breviter paniculate, cataphyllis in rosulis exterioribus cinctae, cataphylla ovatitriangularia, $2-20 \mathrm{~mm}$ longa; flores tetrameri, vinacei vel purpurei, $\pm 5 \mathrm{~mm}$ longi, $\pm 7 \mathrm{~mm}$ lati, dense glanduloso-pubescentes, petala reflexa, ovarium biloculare; drupae tivalvatae, 8-10 $\mathrm{mm}$ longae, 5-6 $\mathrm{mm}$ latae, admondum glabrae, pyrenae nigrae, psedoarillo rubro-aurantiaco partim indutae.

Arbol dioico de $4-6 \mathrm{~m}$ de alto, de corteza lisa no exfoliante, gris clara, plomiza, muy brillante y conspicua, incluso a gran distancia; de copa ancha y algo redondeada; las ramificaciones irregulares; resina de aroma suave y escasa. Hojas compuestas, de $15-28 \mathrm{~cm}$ de largo y $9-17.5 \mathrm{~cm}$ de ancho, con 4-6 pares de foliolos; insertas en los extremos de ramillas laterales y terminales; foliolos de forma oblanceolada, con el margen dentado desde cerca de la base hasta el ápice, los dientes simples a dobles, de $1 \mathrm{~mm}$. de largo y 1-2 mm de ancho, de 10-20 por cada lado; ápice agudo o cortamente acuminado; tomentoso en ambas caras (lanudo-tomentosos en la juventud) 


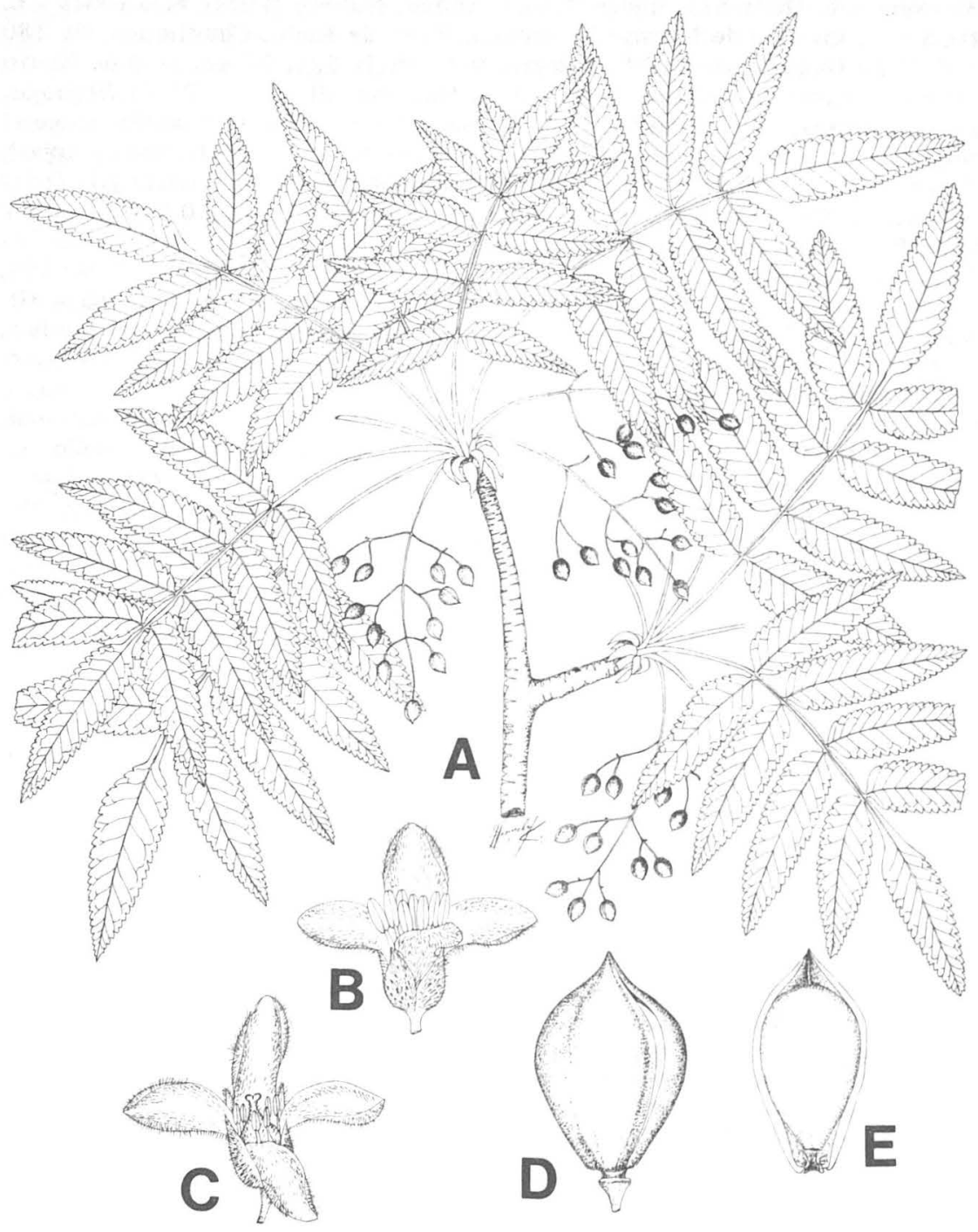

Fig. 3. Brusera sarukhanii Guevara etRzedowski A. Rama con hojas y frutos, X 0.3 ; B. Flor masculina, X 4.5; C. Flor femenina, X 4.5; D. Fruto, X 2; E. Semilla, X 2.1 
con pelos blancos de 1-1.5 mm de largo, el haz de color verde más obscuro que el envés; miden de 5.5-9.5 cm de largo y 1.2-2.5 cm de ancho; el foliolo terminal de base cuneada es 1.5 veces mayor que el par inmediato inferior, los intermedios más largos que los superiores o inferiores. Peciolos de 4.5-9 cm de largo, con la base ensanchada hasta unos 5-6 mm, acanalados en la cara superior; con numerosos pelos glandulosos cortos y amarillentos, que persisten aún en la madurez, entremezclados con pelos blanquecinos eglandulares menos numerosos, más largos, sedosos, algo enrollados y de 1-2 mm. de largo. Raquis alado, de 1-4 mm de ancho, igualmente pubescente e incluso con un manchoncito de pelos en las axilas de los foliolos; de margen entero o menos comunmente dentado, las alas sucesivamente menos conspicuas hacia los internodos inferiores; los internodos de $1.5-2.3 \mathrm{~cm}$ de largo. Inflorescencias insertas en los extremos de las ramillas terminales y laterales, rodeadas en su base por varias series de rosetas de catáfilas deciduas, que miden de 2-20 mm de largo y 3-7 mm de ancho, de forma ovado-triangular, con 1-3 apículos inconspicuos y de color rojizo obscuro, esparcidamente pubescentes en la cara externa, densamente en la cara interna, los pelos de color blanquecino se aglutinan mayormente hacia el ápice de la cara interior y se mezclan con pelos glandulosos cortos, con los bordes muy cortamente laciniados, las series de catáfilas interiores sucesivamente más grandes. Inflorescencias de tipo paniculado con una a dos ramificaciones, con numerosas flores, miden de $2.5-9 \mathrm{~cm}$ de largo; brácteas angostamente lanceoladas, de 2-10 $\mathrm{mm}$ de largo (algunas veces se presentan foliosas), bracteolas lineares, de 1-2 mm de largo; todas las partes de la inflorescencia: pedúnculos, pedicelos, brácteas y bracteolas, cubiertas densamente de pelos glandulosos amarillos de menos de $1 \mathrm{~mm}$ de largo, entre los cuales se esparcen pelos blanquecinos hasta de $1 \mathrm{~mm}$ de largo; las inflorescencias masculinas más largas $(5-9 \mathrm{~cm})$ que las femeninas $(2.5-6$ $\mathrm{cm}$ ). Flores masculinas de $\pm 7 \mathrm{~mm}$ de ancho, sobre pedicelos de 1-3 $\mathrm{mm}$ de largo; sépalos 4, ovado-triangulares, subiguales, con el ápice agudo, de color rojizo y de $1.5-2 \mathrm{~mm}$ de largo y $0.8 \mathrm{a} 1 \mathrm{~mm}$ de ancho, esencialmente glabros en la cara interna, excepto en el ápice, la cara externa cubierta de pelos glandulosos amarillentos, mezclados con escasos pelos blanquecinos largos, erectos y principalmente cistribuídos en los bordes. Pétalos 4 , de color vino rosado a púrpura, oblanceolados, reflejos, de $4.5-5 \mathrm{~mm}$ de largo y $2 \mathrm{~mm}$ de ancho; la cara externa densamente pubescente con pelos blanquecinos largos, rectos, mezclados con pelos glandulosos cortos y amarillentos; la cara interna menos pubescente. Estambres 8, libres, de 2.5 a 3 $\mathrm{mm}$ de largo, filamentos de 1-2 $\mathrm{mm}$ de largo, de base ensanchada con tintes rosados, muy cortamente papilados y con los bordes inconspicuamente laciniados; anteras fértiles de $0.5-1.5 \mathrm{~mm}$ de largo. Ovario residual de menos de $0.5 \mathrm{~mm}$ de largo. Flores femeninas de $5 \mathrm{~mm}$ de largo y $7 \mathrm{~mm}$ de ancho, sobre pedicelos de $2-5 \mathrm{~mm}$ de largo; sépalos 4, de 2-3 $\mathrm{mm}$ de largo y 1-1.5 $\mathrm{mm}$ de ancho, pétalos 4 , de $5 \mathrm{~mm}$ de largo y $2 \mathrm{~mm}$ de ancho, tanto el cáliz como la corola de textura, forma, color y pubescencia similares a los de las flores masculinas. Estaminodios 8, libres, de 1.5 $-2 \mathrm{~mm}$ de largo, con los filamentos de base ensanchada; anteras de $0.5-1 \mathrm{~mm}$ de largo. Ovario bilocular, con pelos glandulosos cortos y amarillentos, estilo bifurcado, cubierto con pelos blanquecinos erectos y agudos, estigmas cortamente papilosos.

Infrutescencias de $5-11 \mathrm{~cm}$ de largo, con varios frutos (3-10); drupas bivalvares, obovoides, de 8-10 mm de largo y 5-6 $\mathrm{mm}$ de ancho, pedicelos de 3-5 $\mathrm{mm}$ de largo; pseudoarilo de color rojo anaranjado cubriendo $2 / 3$ del endocarpio negro. Drupas y 
pedicelos esencialmente glabros, raquis y pedúrculos con glándulas sésiles y algunos pelos blanquecinos dispersos.

Florece desde finales de abril hasta finales de junio y desprende sus hojas hacia el final del año.

Tipo: MEXICO: MICHOACAN: $1 \mathrm{~km}$ al 0 de Naranjo de Tzintzícuaro cerca de Tirindales, Mpio. de La Huacana, bosque tropical caducifolio muy perturbado, sobre suelos someros y pedregosos, altitud $450 \mathrm{~m}, 18$ de julio de 1979, hojas y frutos medianamente maduros; F. Guevara F., M. Sousa, L. Ortíz, J. Diaz, A. Morelos y R. Sousa 682 (ENCB).

El nombre de esta especie está dedicado al Dr. JOSE SARUKHAN KERMEZ, distinguido ecólogo e investigador del Instituto de Biología de la UNAM.

En virtud de su ovario bilocular, flores tetrámeras y la presencia de catáfilas, Bursera sarukhanii pertenece a la sección Bullockia y tomando en consideración algunos caracteres de la morfología floral y de la morfología de la hoja (ver cuadro) se ponen de manifiesto sus afinidades con Bursera bicolor (Willd. ex Schlechtendal) Engl. y Bursera vejar-vasquezii Miranda, de las cuales por otro lado es indudablemente diferente. Es pertinente señalar que McVaugh \& Rzedowski (1965) habían distinguido a B. bicolor como especie única de uno de los 6 grupos en que tentativamente dividieron la sección Bulloclia; anteriormente Miranda (19.42) hizo notar la posible afinidad existente entre B. bicolor y B. vejar-vazquezii. En el cuadro anexo se resumen algunas de las diferencias y semejanzas entre estas dos especies y $\mathrm{B}$. sarukhanii.

El análisis comparativo pone de manifiesto las afinidades existentes entre los tres taxa y sugiere que probablemente constituyen un grupo natural caracterizado por sus inflorescencias paniculadas relativamente grandes y conspicuas, con numerosas flores; flores tetrámeras relativamente grandes, de color vino-rosado a púrpura, con pétalos reflejos y todas las partes florales densamente pubescentes; con hojas grandes y numerosos foliolos dentados y pubescentes; raquis alado y con resina aromática de olor agradable. Por otro lado el cuadro permite diferenciar a B. sarukhanii, por el color gris-claro brillante de su tronco, la resina menos aromática, los 9-13 foliolos, la distancia interfoliar que es menor que en las otras dos especies, los foliolos con dientes simples y dobles, el ápice agudo y cortamente acuminado, las conspicuas alas del raquis foliar; los sépalos pequeños y aovado-triangulares, los frutos ovoides más pequeños, cortamente apiculados y glabrescentes; los pedicelos de las flores de tamaño intermedio respecto a las otras dos especies, el eje de la infloresencia liso. Asimismo difiere por su amplitud altitudinal que es relativamente estrecha y varía de 160-450 m.s.n.m. y por su distribución que, al igual que las otras dos especies descritas en el presente trabajo, se restringe a la parte más baja de la Cuenca del Balsas en los límites de Michoacán y Guerrero.

Ejemplares adicionales utilizados en la descripción:

MEXICO: MICHOACAN: $50 \mathrm{~km}$ north of Arteaga, between Río Tepalcatepec and Arteaga, along the highway south from Cuatro Caminos, Mpio. de Arteaga, alt. $500 \mathrm{~m}, 24$. II.65 (hojas), R. McVaugh 22529 (ENCB); $12 \mathrm{~km}$ al SE de Poturo y a 5 $\mathrm{km}$ a NO de la Candelaria, sobre el camino a Nuevo Churumuco, Mpio. de La Huacana, alt. $450 \mathrm{~m}, 15 . \mathrm{IX} .78$ (hojas y frutos), F. Guevara $9 ; 6 \mathrm{~km}$ al N. de Nuevo Churumuco, sobre el camino a Poturo, Mpio. de La Huacana, alt. $225 \mathrm{~m}$, 15.IX.78 (hojas y frutos), F. Guevara 11;2 km al E de Zicuirán, rumbo a Nuevo Churumuco, 
Mpio. de La Huacana, alt. $310 \mathrm{~m}, 16 . I X .78$ (hojas y frutos) F. Guevara $25 ; 5 \mathrm{~km}$ al NE de Zicuirán, hacia La Huacana, Mpio. de La Huacana, alt. 240 m, 11.X.78 (hojas y frutos), F. Guevara y J. Rzedowski $44 ; 4 \mathrm{~km}$ al S de la desv. Infiernillo-Arteaga, rumbo al poblado de Infiernillo, Mpio. de Arteaga, alt. 400 m, 11.X.78 (hojas y frutos), F. Guevara y J. Rzedowski 51; la Cañada de Huaricho, $9 \mathrm{~km}$ al SE de Poturo, rumbo a Nuevo Churumuco, Mpio. de La Huacana, alt. 390 m, 24.VI.79 (hojas), F. Guevara y L. Ortíz 509; $11 \mathrm{~km}$ al SE de Poturo, rumbo a Nuevo Churumuco, Mpio. de La Huacana, alt. 370 m, 24.VI.79 (hojas y flores), F. Guevara y L. Ortíz 515; ibid., 24.VI.79, (botones, flores y frutos), F. Guevara y L. Ortíz 517; $2 \mathrm{~km}$ al $\mathrm{S}$ de la Candelaria rumbo a Nvo. Churumuco, Mpio. de La Huacana, alt. $340 \mathrm{~m}$, 24.IV.79 (frutos y hojas), F. Guevara y L. Ortíz $521 ; 4 \mathrm{~km}$ al O de Nuevo Churumuco, rumbo a Zicuirán, Mpio. de Nuevo Churumuco, alt. $180 \mathrm{~m}, 25 . V I .79$ (hojas y frutos), F. Guevara y L. Ortíz $525 ; 33 \mathrm{~km}$ al O de Nuevo Churumuco, rumbo a Zicuirán, Mpio. de La Huacana, alt. 190 m, 25.VI.79 (hojas y flores), F. Guevara y L. Ortíz 535; ibid., 25.VI.79 (hojas y flores), F. Guevara y L. Ortíz, 536; $3 \mathrm{~km}$ al E del Jazmín, entre el Jazmín y Zicuirán, Mpio. de La Huacana, alt. 340 m, 25.VI. 79 (hojas y frutos), F. Guevara y L. Ortíz $546 ; 3 \mathrm{~km}$ al NE de Zicuirán, rumbo a La Huacana, Mpio. de La Huacana, alt. 250 m, 1.VII.79 (hojas), F. Guevara y J. Díaz 592; ibid., 1.VII.79 (flores, hojas y frutos), F. Guevara y J. Díaz $595 ; 2 \mathrm{~km}$ al S de la desv. Infiernillo-Arteaga, rumbo a Infiernillo, Mpio. de Arteaga, alt. $320 \mathrm{~m}, 1$.VII. 79 (flores y hojas), F. Guevara y J. Díaz 602; ibid., 1.VII.79 (flores y hojas), F. Guevara y J. Díaz $610 ; 28 \mathrm{~km}$ al SE de Cuatro Caminos, rumbo a la desv. Arteaga Infiernillo, Mpio. La Huacana, alt. 380 m, 20.VII.79 (hojas), F. Guevara, M. Sousa, L. Ortíz, J. Díaz, A. Morelos y R. Sousa 739; Cupuancillo, Mpio. de La Huacana, alt. 400 m, 20.IX.79 (frutos), X. Madrigal S. 3389; carr. Cuatro Caminos-Playa Azul, $3 \mathrm{~km}$. al SE de la desv. a Infiernillo, Mpio. de Arteaga, alt. $375 \mathrm{~m}$, 17.IX.79 (hojas), J. Soto y G. Silva 1632 (MEXU).

GUERRERO: $1 \mathrm{~km}$ al $\mathrm{S}$ de las Juntas de Jacarán, 27.IV.79, (botones y flores), C. Toledo y M. Blanco 927 (ENCB); 7 km. al S de Hacienda Vieja, 25.IV.79 (botones y flores), C. Toledo y M. Blanco 917 (ENCB); $7 \mathrm{~km}$ al S de Hacienda Vieja, 25.IV. 79 (botones y flores), C. Toledo y M. Blanco 918 (ENCB); $12 \mathrm{~km}$ al SE de la cortina de la presa de Infiernillo, rumbo a la Unión, alt. $160 \mathrm{~m}, 25$. VIII.79 (hojas), F. Guevara, L. Ortíz, J. Díaz, R. Sánchez 809.

\section{AGRADECIMIENTOS}

Al Biól. Sócrates Cisneros Paz, Director de la Escuela de Biología de la U.M.S.N.H. y Coordinador General del proyecto "CONTRIBUCION AL ESTUDIO DE LOS RECURSOS BIOTICOS DEL ESTADO DE MICHOACAN" por las facilidades y apoyo brindados. A los Srs. Jorge Díaz C., Luis Ortíz A. y Rodolfo Sánchez, estudiantes de la misma Escuela y colaboradores del proyecto. Al Biól. Xavier Madrigal S. y al Dr. Rogers McVaugh, quienes desde hace algunos años habían colectado las tres especies descritas y amablemente pusieron a nuestra disposición su material y datos referentes.

Asimismo se agradece la colaboración del Biól. José Magaña M., Jefe del herbario de la Escuela de Biología de la U.M.S.N.H., al Pasante de Biología José C. Soto N. 


\begin{tabular}{|c|c|c|c|}
\hline & Bursera sarukhanii & Bursera bicolor & Bursera vejar-vazquezii \\
\hline PECIOLOS & $\begin{array}{l}\text { densamente pubescentes solo cuando jó- } \\
\text { venes, con pelos blanquecinos cortos inter- } \\
\text { calados con pelos glandulosos cortos muy } \\
\text { abundantes }\end{array}$ & $\begin{array}{l}\text { densamente pubescentes solo cuando } \\
\text { jóvenes, con pelos blanquecinos cortos } \\
\text { intercalados con pelos glandulosos cortos }\end{array}$ & $\begin{array}{l}\text { densamente pubescentes } \\
\text { aún en la madurez con pelos } \\
\text { ferrugineos mayormente } \\
\text { concentrados hacia la base }\end{array}$ \\
\hline $\begin{array}{l}\text { No. DE } \\
\text { FOLIOLOS }\end{array}$ & $9-13$ & $13-17$ & $13-15$ \\
\hline $\begin{array}{l}\text { FORMA DE } \\
\text { FOLIOLOS }\end{array}$ & oblanceolados & angostamente lanceolados & largamente lanceolados \\
\hline $\begin{array}{l}\text { DISTANCIA } \\
\text { INTERFOLIAR }\end{array}$ & $1.5-2.3 \mathrm{~cm}$ & $1-2 \mathrm{~cm}$ & $2-4 \mathrm{~cm}$ \\
\hline APICE & agudo, cortamente acuminado & acuminado, de más de $5 \mathrm{~mm}$ de largo & atenuado, de $5 \mathrm{~mm}$ de largo \\
\hline HAZ DEL & & & \\
\hline FOLIOLO & $\begin{array}{l}\text { opaco, pubescente, con nervaduras poco } \\
\text { marcadas }\end{array}$ & $\begin{array}{l}\text { glabro, algo brillante, con nervaduras } \\
\text { impresas y conspicuas }\end{array}$ & $\begin{array}{l}\text { opaco, pubescente, con ner- } \\
\text { vaduras poco marcadas }\end{array}$ \\
\hline ENVES DEL & & $\cdot$ & \\
\hline FOLIOLO & $\begin{array}{l}\text { pubescente, con pelos largos y más } \\
\text { dispersos, con nervaduras prominentes } \\
\text { y reticuladas }\end{array}$ & $\begin{array}{l}\text { glauco, densamente tomentoso, los pe- } \\
\text { los cortísimos y apretados, con nerva- } \\
\text { duras inconspicuas }\end{array}$ & $\begin{array}{l}\text { pubescente, los pelos lar- } \\
\text { gos y más dispersos, con } \\
\text { nervaduras prominentes } \\
\text { y reticuladas }\end{array}$ \\
\hline ALAS DEL & & & \\
\hline RAQUIS & $\begin{array}{l}\text { conspicuas, de } 1-4 \mathrm{~mm} \text { de ancho, } \\
\text { algunas veces las superiores } \\
\text { dentadas }\end{array}$ & $\begin{array}{l}\text { conspicuas, de } 1-5 \mathrm{~mm} \text { de ancho, } \\
\text { enteras }\end{array}$ & $\begin{array}{l}\text { residuales e inconspicuas } \\
\text { de } 0.5 \mathrm{~mm} \text { de ancho, } \\
\text { enteras }\end{array}$ \\
\hline SEPALOS & $\begin{array}{l}\text { aovado-triangulares, de } 1.5-3 \mathrm{~mm} \\
\text { de largo y de } 0.8-2 \mathrm{~mm} \text { de ancho, } \\
\text { con abundantes pelos glandulosos }\end{array}$ & $\begin{array}{l}\text { angostamente lanceolados, de } 5-6 \mathrm{~mm} \\
\text { de largo y } 1 \mathrm{~mm} \text { de ancho, con abun- } \\
\text { dantes pelos glandulosos }\end{array}$ & $\begin{array}{l}\text { lineares, de } 4-5 \mathrm{~mm} \text { de lar- } \\
\text { go y de } 1-1.5 \mathrm{~mm} \text { de } \\
\text { ancho, con pelos glandulo- } \\
\text { sos escasos o ausentes }\end{array}$ \\
\hline
\end{tabular}




\begin{tabular}{|c|c|c|c|}
\hline PETALOS & $\begin{array}{l}\text { de } 4-5 \mathrm{~mm} \text { de largo y } 2 \mathrm{~mm} \text { de ancho, } \\
\text { de color rosa-purpúreo. }\end{array}$ & $\begin{array}{l}\text { de } 6-8 \mathrm{~mm} \text { de largo y de } 1.5 \mathrm{~mm} \text { de } \\
\text { ancho de color rosa-purpúreo. }\end{array}$ & $\begin{array}{l}\text { de } 4-5 \mathrm{~mm} \text { de largo y de } \\
\text { ancho, de color rojizo }\end{array}$ \\
\hline $\begin{array}{l}\text { EJE DE LA } \\
\text { INFLORES- } \\
\text { CIENCIA }\end{array}$ & liso & inconspicuamente estriado a liso & conspicuamente estriado \\
\hline PEDICELO & de $3-5 \mathrm{~mm}$ de largo & de $5-10 \mathrm{~mm}$ de largo & de $1-2 \mathrm{~mm}$ de largo \\
\hline FRUTOS & $\begin{array}{l}\text { obovoides, cortamente apiculados } \\
\text { (apículo de menos de } 1 \mathrm{~mm} \text { de largo) } \\
\text { glabrescentes; de } 8-10 \mathrm{~mm} \text { de largo } \\
\text { y de } 5-6 \mathrm{~mm} \text { de ancho }\end{array}$ & $\begin{array}{l}\text { elipsoidales, largamente apiculados } \\
\text { (apículo de 1-3 mm de largo), pu- } \\
\text { bescentes, los pelos blancos, rectos: } \\
\text { de } 10-14 \mathrm{~mm} \text { de largo y } 5-7 \mathrm{~mm} \text { de } \\
\text { ancho }\end{array}$ & $\begin{array}{l}\text { elipsoidales; cortamente } \\
\text { apiculados, (apículo hasta } \\
\text { de } 1 \mathrm{~mm} \text { de largo), corta- } \\
\text { mente pubescentes, los pe- } \\
\text { los blancos, rectos, de } \\
12-14 \mathrm{~mm} \text { de largo y } \\
7-10 \mathrm{~mm} \text { de ancho }\end{array}$ \\
\hline
\end{tabular}


por el aporte de algunos datos de sus colectas en la región y al Biólogo Alejandro Martínez Mena del Laboratorio de Microcine de la Fac. de Ciencias de la U.N.A.M., por la elaboración del material fotográfico. Los dibujos originales son obra del Sr. Humberto Sánchez C.

El primero de los autores agradece al Dpto. de Biología de la Facultad de Ciencias, las facilidades concedidas a través del programa de Intercambio Académico de la U.N.A.M.

\section{RESUMEN}

Se hace una breve caracterización ambiental de la región del Infiernillo y sus alrededores (Michoacán, México), en donde se distribuyen tres especies nuevas del género Bursera que son: Bursera infernidialis, Bursera paradoxa y Bursera sarukhanii. Se hace la descripción de las mismas con algunas anotaciones acerca de sus afinidades, resaltando el carácter no exfoliante de la corteza de B. paradoxa (perteneciente a la sección Bursera) y sugiriendo que tal característica, si bien es constante en casi todos los miembros de la sección Bullockia del género, no es exclusiva de la misma; por lo que tal rasgo no resulta determinante en la separación y diferenciación de las dos secciones del género Bursera. De igual manera, se destaca la gran similitud existente entre los órganos foliares de esta especie y Commiphora kraeuseliana Heine, que es una especie perteneciente a un género emparentado con Bursera y endémica del SW de Africa.

Tomando en consideración la presencia del número relativamente alto de endemismos, se sugiere que probablemente las diferentes regiones ecológicas de la gran Depresión del Balsas, representan a su vez diferentes centros de diversificación de ciertos grupos de plantas.

\section{SUMMARY}

A brief environmental characterization of the Infiernillo region and its surroundings (Michoacan State, Mexico) is given, where three new species of the genus Bursera: Bursera infernidialis, Bursera paradoxa and Bursera sarukhanii are distributed. A description of these species is presented with notes about their affinities, stressing the non peeling bark of Bursera paradoxa (which belongs to the section Bursera) and suggesting that this feature, although constant in almost all of the group members of the section Bullockia of the genus, is not exclusive of this section. Therefore the non peeling bork proves not to be a determinant feature in the separation and differentiation of the two sections of the genus. In addition the great similiarity is stressed between the leaves of this species and Commiphora Kraeuseliana Heine which is a species belonging to a genus related to Bursera and endemic to Southwest Africa.

Taking into consideration the ocurrence of a relatively high number of endemisms, it is suggested that possibly the different ecological regions of the great Balsas Basin represent different centers of diversification of certain groups of plants. 


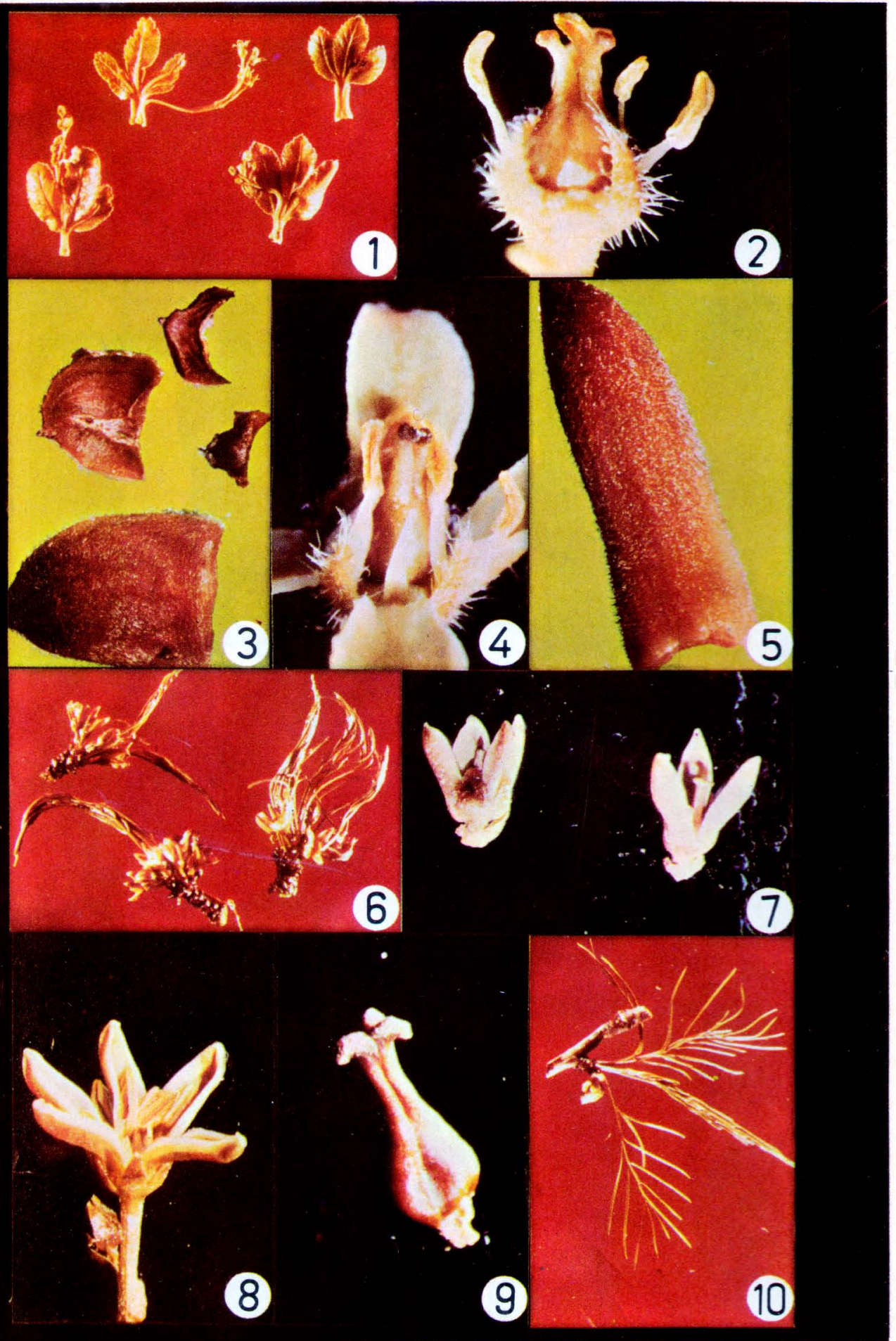

Figura 4. Bursera infernidialis Guevara et Rzedowski. (1), Inflorescencias insertas en la base de las hojas tiernas. (2), Flor femenina desprovista de corola, con sépalos, gineceo y estaminodios. (3), Serie de catáfilas. (4), Flor femenina con sépalos, pétalos, gineceo y estaminodios. (5), Cara externa de una catáfila. Bursera paradoxa Guevara et Rzedowski. (6), Inflorescencias fasciculadas entre las hojas tiernas. (7), Flor femenina, con sépalos, pétalos y gineceo; los estaminodios inconspicuos. (8), Flor masculina con sépalos, pé talos y estambres fértiles bien desarrollados; gineceo residual inconspicuo. (9), Gineceo funcional de una flor femenina. (10), Rama con hojas y frutos tiernos. 


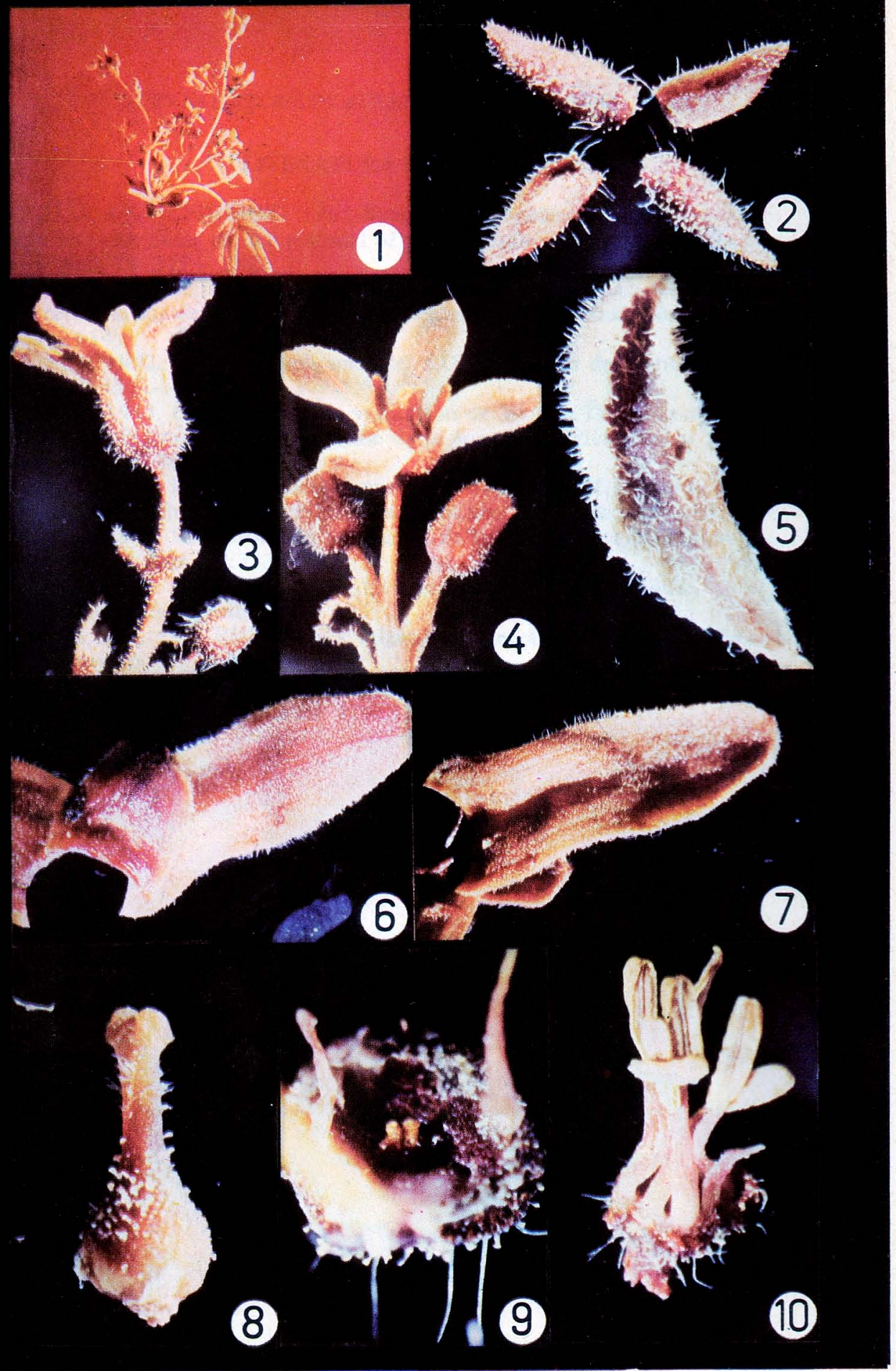

Figura 5. Bursera sarukhanii Guevara et Rzedowski. (1), Inflorescencias entre las hojas tiernas. (2), Sépalos glanduloso-pubescentes. (3), Flor masculina. (4) Flor femenina con estaminodios. (5), Pétalo densamente pubescente. (6), Cara externa de una serie de catáfilas. (7), Cara interna de una serie de catáfilas. (8), Gineceo funcional de una flor femenina. (9), Gieneceo residual de una flor masculina. (10), Estambres fértiles. 


\section{LITERATURA CITADA}

McVAUGH, R. \& J. RZEDOWSKI. 1965. Synopsis of the genus Bursera L.in western México, with notes on the material of Bursera collected by Sessé \& Mociño. Kew Bull. 18: 317 - 382.

MIRANDA, F. 1941. Estudios sobre la vegetación de México. I. La vegetación de los cerros al sur de la Meseta Anáhuac. El cuajiotal. An. Inst. Biol. Méx. 12: $569-614$.

MIRANDA, F. 1942. Nuevas fanerógamas del S.O. del Estado de Puebla. An. Inst. Biol. 13: $451-453$.

MIRANDA, F. 1943. Estudios sobre la vegetación de México. IV. Algunas características de la flora y de la vegetación de la zona de Acatlán, Puebla. An Inst, Biol. Méx. 14: 407 - 421.

MIRANDA, F. 1947. Estudios sobre la vegetación de México. V.Rasgos de la vegetación en la Cuenca del Río de las Balsas. Rev. Soc. Mex. Hist. Nat. 8: 95 - 114.

MIRANDA, F. 1948. Datos sobre la vegetación de la Cuenca Alta del Papaloapan. An Inst. Biol. Méx. 19:333 - 364.

RZEDOWSKI, J. y R. McVAUGH. 1966. La vegetación de la Nueva Galicia. Contr. Univ. Mich. Herb. 9: 1 - 123.

RZEDOWSKI, J y H. KRUSE. 1979. Algunas tendencias evolutivas en Bursera (Burseraceae). Taxon 28: $103-116$.

VAN DER WALT, J.J.A. 1974. A preliminary report on the genus Commiphora in South West Africa. Madoqua ser. 1, 9: 5 - 23. 